\title{
O desenvolvimento de Materiais Autorais Digitais Educacionais na compreensão de Licenciandos sobre Docência em contexto Interdisciplinar
}

\author{
Luciana de Lima $^{1}$, Robson Carlos Loureiro ${ }^{1}$ \\ ${ }^{1}$ Instituto Universidade Virtual - Universidade Federal do Ceará (UFC) \\ Av. Humberto Monte $\mathrm{s} / \mathrm{n}$ - Fortaleza - CE - Brasil \\ \{luciana, robson\}@virtual.ufc.br
}

\begin{abstract}
The goal of this study is to analyze how licentiates understand the teaching on the development of Educational Digital Authorial Materials (EDAM). The research is based on qualitative Case Study. EDAM developed by licentiates as activity Technoteaching discipline are analyzed. It is possible to infer that in general licentiates understand teaching for presentation of content, opting for the use of slides with teaching activities centered on the teacher and difficulty in articulating different knowledge in an interdisciplinary way.

Resumo. $O$ objetivo deste trabalho é analisar como licenciandos compreendem a docência diante do desenvolvimento de Materiais Autorais Digitais Educacionais (MADEs). A pesquisa apresenta caráter qualitativo baseada em Estudo de Caso. São analisados os MADEs desenvolvidos pelos licenciandos como atividade da disciplina Tecnodocência. É possivel inferir que em geral os licenciandos compreendem a docência para apresentação de conteúdos, optando pelo uso de slides com ação docente centrada no professor e dificuldade em articular diferentes conhecimentos de forma interdisciplinar.
\end{abstract}

\section{Introdução}

Atualmente, professores da Educação Básica e Ensino Superior apresentam dificuldades em trabalhar de forma interdisciplinar com o uso das Tecnologias Digitais da Informação e Comunicação (TDICs). De acordo com Tardif (2002), esse fato decorre de uma formação pouco eficiente que ainda se baseia em uma proposta aplicacionista do conhecimento. No caso da formação de licenciandos, Gatti (2010) ressalta a existência de uma pulverização dos conhecimentos, gerando uma fragilidade da preparação dos professores para o exercício da docência na Educação Básica. Os conteúdos são desarticulados, existe um desequilíbrio entre disciplinas teóricas e práticas, e, estão desvinculados das reflexões e possíveis integrações com as tecnologias digitais.

A simples incorporação dos conhecimentos vinculados às tecnologias digitais nos cursos de formação não garante uma transformação pedagógica e integradora de fato, apenas reforça uma prática vigente [Coll 2009]. Loureiro, Lima e Soares (2014) em pesquisa desenvolvida com professores de ensino superior constatam que existe interesse dos docentes em se aprofundar no conhecimento sobre as novidades tecnológicas. No entanto, buscam empregá-las em metodologias para a prática da docência, geralmente de forma expositiva. 
Compreende-se que a fragmentação do conhecimento imposta nas formações de licenciandos pode ser minimizada por meio do desenvolvimento de trabalhos interdisciplinares que procure pela integração entre TDIC e Docência, denominada Tecnodocência. Neste sentido, a interdisciplinaridade pode ser um caminho propício para minimizar o impacto da fragmentação no processo formativo docente. Entende-se por interdisciplinaridade a integração entre saberes que estabelecem necessidades de trocas conceituais entre seus especialistas pelo compartilhamento de conhecimentos, reflexões e discussões conjuntas [Japiassu 1976].

Pesquisas na área revelam que o trabalho da interdisciplinaridade inserido no contexto das TDICs pode ser uma ação promissora para a transformação da ação docente. Amem e Nunes (2006) concordam que esse trabalho é possível e traz contribuições favoráveis, uma vez que permite a utilização de métodos não convencionais de aprendizagem, facilitando a troca de informações, a interação entre os usuários e a integração entre os conhecimentos. Andalécio (2009) revela que as mudanças que advêm com as TDICs são consideradas revolucionárias na execução das tarefas docentes com a construção colaborativa do conhecimento por meio de trocas que envolvem os aspectos culturais. Ressalta, no entanto, que é necessário considerar que a atitude de quem as utiliza é um fator relevante para a instauração de um quadro de mudanças que contribuam de forma significativa para o processo de ensino, aprendizagem e avaliação.

Diante da necessidade explícita de integração entre TDIC e Docência, compreende-se um Material Autoral Digital Educacional (MADE) como sendo todo e qualquer material educacional desenvolvido por um aprendiz utilizando um equipamento digital conectado ou não à internet com criação, planejamento, execução, reflexão e avaliação desenvolvidos pelo próprio aprendiz individualmente ou em grupo como processo ou produto de ensino, aprendizagem e avaliação. Dessa forma, o desenvolvimento de MADEs estão vinculados à utilização de recursos disponíveis na internet bem como os recursos disponíveis em softwares residentes em computadores utilizados off-line para que o professor possa construir de materiais educacionais de forma interdisciplinar com outros professores ou com os alunos a fim de que solucionem desafios que the são apresentados de forma contextualizada. Diante do exposto, pergunta-se: Como o desenvolvimento de MADEs em contexto interdisciplinar influencia a compreensão dos licenciandos sobre docência?

O desenvolvimento desse tipo de Material é pesquisado com professores e alunos de diferentes áreas e em diferentes contextos. Serres e Basso (2009) ao pesquisarem o desenvolvimento de materiais digitais em parceria revelam que professores conseguem saber mais sobre os alunos, redirecionando sua prática pedagógica. Para Barro e Queiroz (2012) a participação de boa qualidade dos alunos aumenta, garantindo maior apropriação do conhecimento. Nascimento e Costa Junior (2015) mostram maior apropriação de conteúdos pelo professor. No entanto, pesquisas como as de Lima e Loureiro (2015) revelam que professores em formação inicial ao desenvolver seus materiais educacionais digitais optam pelos recursos audiovisuais como vídeos e slides, centrando-se em uma ação reprodutivistas do conhecimento.

O objetivo deste trabalho é analisar de que forma os licenciandos transformam sua compreensão sobre docência a partir do desenvolvimento de Materiais Autorais Digitais Educacionais (MADEs) em contexto interdisciplinar. São apresentados os resultados da pesquisa oriundos do projeto IUVI01 cadastrado no Instituto Universidade 
V Congresso Brasileiro de Informática na Educação (CBIE 2016)

Anais do XXII Workshop de Informática na Escola (WIE 2016)

Virtual avaliado e aprovado por seu Comitê de Pesquisa em 2015, compondo um dos trabalhos desenvolvidos pelo Grupo de Pesquisa Tecnodocência cadastrado no Diretório CNPq e certificado pela Universidade Federal do Ceará (UFC).

\section{As Tecnologias Digitais da Informação e Comunicação na Formação de Professores}

As propostas de Formação de Professores que contemplam a integração entre as TDICs e os aspectos educacionais são apresentadas de formas variadas por meio de pesquisas e políticas oriundas de países que consideram o uso da tecnologia digital como uma forma de comunicação global, social e cultural. A inserção do uso das TDICs vincula-se ao processo de desenvolvimento profissional, muitas vezes pensada para as formações continuadas de professores. No entanto, podem ser consideradas também no processo de formação inicial.

A proposta da Unesco (2002) se apresenta em quatro estágios. Inicialmente há a necessidade do desenvolvimento de habilidades e conhecimentos dos professores sobre os aspectos tecnológicos. Realizar tarefas pessoais e profissionais utilizando os recursos da internet, de softwares mais comuns como editores de texto, planilhas eletrônicas e slides auxiliam na compreensão das possibilidades relacionadas ao uso da tecnologia digital. Em um segundo momento, é necessário que o professor aprenda a aplicar as TDICs para aprimorar a aprendizagem de seus alunos e sua própria aprendizagem. Neste momento, o professor se torna capaz de reconhecer as funcionalidades das tecnologias, adequando-as às preferências dos alunos por meio do desenvolvimento de projetos e atividades pautadas na resolução de problemas.

É somente após esses dois passos iniciais que os professores contemplarão a transformação pedagógica. Neste momento, deverão aprender a integrar as características da tecnologia digital aos objetivos didático-pedagógicos diante de um trabalho colaborativo pautado na construção do conhecimento. Porém, a apropriação dessa ação não acontece de forma imediata. É preciso que os resultados obtidos sejam compartilhados, discutidos e refletidos de forma colaborativa com seus pares, colegas e especialistas, para que as mudanças sejam, de fato, efetivadas e incorporadas ao fazer pedagógico. É importante destacar que os saberes oriundos das TDICs não devem ser considerados de forma isolada, nem tampouco, especiais em relação aos demais saberes necessários à docência. $\mathrm{O}$ estudo dos saberes das TDICs requer uma compreensão ainda maior dos conteúdos disciplinares, pedagógicos e das relações estabelecidas entre eles. [Almeida e Valente 2011].

O uso das TDICs na prática docente permite então que o professor centre suas ações na elaboração de projetos, na proposição de problemas, no trabalho com temas geradores, no desenvolvimento de atividades que despertem a curiosidade dos alunos com o objetivo de descobrir fenômenos, aprender com as descobertas dos colegas a partir da compreensão dos problemas reais inerentes aos diferentes contextos nos quais se insere [Almeida e Valente 2011].

A visão internacional para o uso das TDICs na Formação de Professores não se diferencia daquela que se almeja nas propostas brasileiras. Estudos realizados no Quebec sobre o referencial das competências profissionais para os futuros professores ressaltam que a apropriação das TDICs para o planejamento, a condução das aulas e a gestão do ensino são imprescindíveis para a prática docente. O professor deve saber se 
comunicar com a ajuda das TDICs, bem como planejar e ensinar com elas, estimulando seus alunos a utilizarem-nas para aprenderem melhor. Corroborando com as ideias até então apresentadas, os professores devem utilizar as TDICs como ferramentas que promovam sua própria aprendizagem. Ressaltam, no entanto, que a integração pedagógica entre as TDICs e o ensino deve acontecer de modo transversal [Karsenti, Villeneuve e Raby 2008].

Ao se trabalhar no contexto das TDICs, esse objetivo é alcançado quando são possibilitados recursos que permitam a exploração, a investigação e a descoberta. Ao se trabalhar dentro dessa perspectiva construcionista de aprendizagem alguns aspectos relevantes se evidenciam. A aprendizagem se torna efetiva por meio da construção do conhecimento, pela liberdade de ação e pela reflexão a partir dos erros cometidos no processo. Os feedbacks enviados pelo sistema em uso, considerados importantes para o processo de aprendizagem, são gerados como função de escolhas e de ações do aprendiz dentro do sistema. O computador deve ser utilizado como uma máquina a ser ensinada. A partir de suas premissas, o aprendiz deve inserir seu conjunto de ideias para obter a resposta de suas próprias ações [Valente 2002].

Viseu e Ponte (2012) ao estudarem a influência das TDICs no desenvolvimento do conhecimento didático de licenciandos de Matemática e de sua capacidade reflexiva na fase do estágio, percebem que possibilitam o desenvolvimento de uma autoavaliação sobre a prática e a ampliação desse conhecimento ao comparar suas ações docentes com a de outros colegas. Apesar de utilizarem apenas e-mail e fórum como ferramentas digitais para discussão e troca de experiências, os resultados foram satisfatórios. O email auxiliou os sujeitos da pesquisa a desenvolverem sua capacidade reflexiva, permitindo-os pensar antes de escrever, diferentemente do que se faz em uma discussão presencial, além de confrontar suas opiniões com as de outros colegas. O fórum foi considerado mais do que um ponto de encontro entre colegas e orientadores, mas principalmente um ponto de confronto de ideias, o que permitiu discussões fundamentadas em leituras e pautadas nas experiências da prática docente. De acordo com os licenciandos, o repensar durante as discussões virtuais desenvolve a capacidade de questionar.

Quando se trata de desenvolvimento de Material Didático de Autoria os incrementos nos processos de ensino e de aprendizagem se tornam evidentes, com diferentes possibilidades de ação pedagógica. Serres e Basso (2009) ao trabalhar com diários virtuais desenvolvidos pelos próprios alunos em disciplina de Matemática constatam que a informação apresentada pelos alunos ajuda o professor a entender suas dificuldades de aprendizagem, permitindo-lhe redirecionar seu fazer pedagógico, além de possibilitar uma abertura do canal de comunicação entre professor e alunos. Inferem que o desenvolvimento de um trabalho integrado entre fotografia e funções matemáticas promove a cooperação no trabalho em equipe, possibilitando o desenvolvimento de estratégias de aprendizagem próprias com autonomia na ação.

Para Barro e Queiroz (2012) o desenvolvimento de blogs em disciplina de comunicação científica por professores e alunos permite ao aluno um protagonismo no processo de ensino e aprendizagem. Os sujeitos da pesquisa apresentam interação por meio de publicação de mensagens vinculadas às atividades solicitadas pelos professores, de reflexões sobre o desenvolvimento das propostas apresentadas e de comentários em qualquer horário do dia. Compreendem que a quantidade de mensagens publicadas depende do feedback do professor, gerando mais publicações e melhor uso dos blogs 
V Congresso Brasileiro de Informática na Educação (CBIE 2016)

Anais do XXII Workshop de Informática na Escola (WIE 2016)

por parte dos alunos.

Nascimento e Costa Junior (2015) ao utilizar o Visual Class com professores da Educação de Jovens e Adultos (EJA) compreendem a importância da utilização do software de autoria para a produção de conteúdos pelo professor que se caracterizam principalmente como videoaulas de conteúdos variados. Com isso, percebem maior apropriação dos conteúdos por parte dos professores e possivelmente maior engajamento no uso das tecnologias digitais com os alunos em sala de aula.

Percebe-se a importância de uma formação inicial que vislumbre não só a integração entre os diferentes saberes, sejam eles específicos, pedagógicos ou tecnológicos digitais, mas principalmente uma ação metodológica diferenciada do professor que permita a compreensão de parcerias com outros profissionais e principalmente com os alunos. Tornando-se protagonista no processo formativo, o licenciando pode adquirir conhecimentos importantes para atuar de forma diferenciada e inovadora, diante de produções autorais com seus alunos fazendo uso das TDICs.

\section{Metodologia}

A pesquisa de caráter qualitativo utiliza como metodologia o Estudo de Caso. Essa escolha se justifica pelo fato de investigar um fenômeno contemporâneo, considerandose o contexto real de estudantes de Licenciatura da Universidade Federal do Ceará; de considerar a não exigência de controle sobre os eventos comportamentais, valorizando a expressão espontânea do pensamento dos sujeitos investigados; e de utilizar fontes de evidências diretas na compreensão dos fenômenos estudados [Yin 2005].

São apresentados os resultados da pesquisa oriundos do projeto IUVI01 cadastrado no Instituto Universidade Virtual avaliado e aprovado pelo Comitê de Pesquisa em 2015, compondo um dos trabalhos desenvolvidos pelo Grupo de Pesquisa Tecnodocência cadastrado no Diretório de Pesquisa do CNPq e certificado pela UFC. A unidade de análise é composta por cinco (5) grupos interdisciplinares de estudantes formados por um máximo de quatro (4) integrantes, oriundos de diferentes cursos de Licenciatura da Universidade Federal do Ceará, participantes da disciplina Tecnodocência no semestre 2015.2, ofertada com 32 vagas pela Pró-Reitoria de Graduação (ProGrad) com apoio do Instituto Universidade Virtual (IUVI). O local utilizado para a realização da pesquisa é o Laboratório Interdisciplinar de Formação de Educadores (LIFE/UFC) às sextas-feiras de 14h às $18 \mathrm{~h}$. O local e os equipamentos são cedidos pela Pró-Reitoria de Graduação da UFC (ProGrad).

A turma é composta por vinte e quatro (24) estudantes, dezessete (17) homens e sete (7) mulheres. São oriundos das Licenciaturas em Ciências Biológicas, Educação Física, Filosofia, Física, Geografia, Letras, Matemática, Música e Química. A faixa etária média do grupo é de vinte e cinco (25) anos. Cinco (5) integrantes estão cursando os primeiros semestres de seus respectivos cursos, sete (7) integrantes estão nos semestres intermediários e doze (12) estão cursando os últimos semestres. Todos eles utilizam computador e internet. Dezesseis (16) preferem utilizar em casa, seis (6) preferem utilizar na Universidade e os demais, utilizam no trabalho. Vinte e dois (22) utilizam todos os dias, os outros dois (2) fazem uso três vezes por semana. Navegam principalmente pelas redes sociais, por sites sobre profissão e trabalho, trabalhos acadêmicos, jogos e entretenimento. 
A disciplina Tecnodocência tem como objetivo formar estudantes que queiram atuar como docentes diante da utilização de uma proposta metodológica interdisciplinar integrada às TDICs pautada no estudo teórico-prático da Teoria da Aprendizagem Significativa de Ausubel [Ausubel, Novak e Hanesian 1980], da Teoria de Fluxo de Czikszentmihalyi (1990), da Filosofia da Diferença com enfoque em Foucault (1979), dos conceitos de Interdisciplinaridade ressaltados por Japiassu (1976) e da proposta de utilização das Tecnologias Digitais em processos de Ensino e Aprendizagem apresentada por Papert (2008). Possibilita a valorização e a utilização dos conhecimentos prévios dos participantes, a construção do engajamento e do significado do conceito de tecnologia, docência e tecnodocência, e, o desenvolvimento do pensamento crítico-reflexivo sobre a ação da prática docente.

A pesquisa está concebida em três (3) etapas: planejamento, coleta de dados e análise de dados. Na primeira, são preparadas as estratégias, os protocolos, os instrumentos e a política de armazenamento de informações na coleta de dados, bem como, as estratégias, os instrumentos e as formas de armazenamento de informações na análise dos dados. Além disso, são preparados os equipamentos para o desenvolvimento dos MADEs.

Na segunda etapa, é realizada a coleta de dados a partir da investigação sobre a forma como os licenciandos concebem, desenvolvem e propõem os MADEs. Inicialmente são realizadas discussões e compreensões teóricas a respeito dos conceitos de interdisciplinaridade e MADE por meio de buscas de informações e análise de práticas docentes. Os grupos interdisciplinares são definidos e cada um escohe seu tema de trabalho, os conteúdos envolvidos e os objetivos a serem alcançados para o desenvolvimento de uma prática docente interdisciplinar. Elaboram roteiros de desenvolvimento dos MADEs, bem como, executam as ações necessárias para sua concretização diante da articulação dos conteúdos.

É utilizado um (1) protocolo de coleta de dados considerando-se os seguintes aspectos: apresentação dos objetivos gerais do projeto de pesquisa, dos objetivos específicos da coleta, da descrição das atividades desenvolvidas, de questões necessárias para nortear o trabalho no momento da execução das atividades e um guia para a elaboração do relatório do estudo de caso.

A análise de dados ocorre pela interpretação dos discursos utilizados pelos grupos interdisciplinares explícitos nos roteiros desenvolvidos para a elaboração dos MADEs em comparação com o processo de observação realizado durante a execução da atividade com os licenciandos e o referencial teórico utilizado como base para a pesquisa bibliográfica. Para isto, é utilizada uma triangulação metodológica, favorecendo a comparação das informações em diferentes instrumentos da pesquisa, a fim de verificar as convergências e divergências das interpretações de forma linear [Stake 2010].

A análise de dados se subdivide em três (3) focos: compreensão dos aspectos vinculados à interdisciplinaridade; compreensão dos aspectos vinculados às tecnologias digitais; compreensão dos aspectos vinculados ao centro da ação docente. No primeiro foco são analisados os seguintes elementos: como os grupos compreendem e utilizam a interdisciplinaridade; quais as dificuldades que apresentam ao trabalhar de forma interdisciplinar no desenvolvimento dos MADEs. No segundo foco são analisados os seguintes elementos: quais os recursos digitais escolhidos para o desenvolvimento dos 
V Congresso Brasileiro de Informática na Educação (CBIE 2016)

Anais do XXII Workshop de Informática na Escola (WIE 2016)

MADEs e de que forma pensam a docência nesse desenvolvimento. No terceiro foco são analisados: de que forma os licenciandos direcionam a ação docente; como propõem a utilização dos MADEs na docência.

\section{Resultados e Discussão}

Os resultados são apresentados a partir das três (3) etapas da pesquisa diante da interpretação dos discursos utilizados nos questionários e nos MADEs, seguido de interpretação e discussão à luz do referencial teórico utilizado. Os grupos interdisciplinares pesquisados são intitulados de G1, G2, G3, G4 e G5 a fim de evitar dubiedade em relação à linguagem utilizada no texto.

Os MADEs foram desenvolvidos pelos próprios licenciandos, integrantes dos grupos interdisciplinares. No total, foram desenvolvidos cinco (5) MADEs com características próprias para atender o trabalho docente interdisciplinar, considerando-se cada área específica de saber dos licenciandos. O G1 desenvolveu slides que apresentam informações sobre a cultura islâmica com charges em francês, gifs explicativos sobre ligações químicas e a energia liberada em bombas utilizadas em ataques terroristas. $\mathrm{O}$ G2 desenvolveu apresentação no Prezi sobre elementos existentes no telefone celular, tais como os elementos químicos da bateria que podem causar câncer, como esse câncer invade o corpo humano, as músicas que podem ser ouvidas no aparelho e sua conexão com elementos literários. O G3 desenvolveu apresentação em slides utilizando trechos do filme Matrix para explicar o fototropismo, a lei da gravidade e a jornada do herói como narrativa. O G4 desenvolveu apresentação em slides utilizando trechos do filme Homem Formiga para explicar a Lei atômica de Rutherford, o roteiro de cinema como gênero textual e a discussão sobre as problemáticas sociais apresentadas no filme. O G5 desenvolveu apresentação em slides utilizando imagens sobre a obra Guernica de Pablo Picasso e cartazes da guerra civil espanhola para explicar sobre Imperativo no Espanhol, bem como simuladores digitais para explicar o lançamento de projéteis.

A utilização de um tema comum para todos os grupos auxiliou na produção de materiais mais próximos do conceito de interdisciplinaridade. As propostas remetem ao tema central e contribuem para que as apresentações apresentem contextualizações. No entanto, cada slide se apresentou como uma relação direta entre o conteúdo específico de determinada área do saber com o tema, havendo poucas conexões entre as diferentes áreas. Os licenciandos apresentaram dificuldade em explicitar essa conexão e em desenvolver um slide comum a todos os saberes.

Para Japiassu (1976) a interdisciplinaridade pode ser um caminho propício para minimizar o impacto da fragmentação dos saberes. Andalécio (2009) afirma que ao inserir as TDICs no contexto da docência o processo de construção colaborativa do conhecimento por meio das trocas culturais é favorecido. No entanto, vivenciar esse processo na prática requer o engajamento dos sujeitos envolvidos e o trabalho com subjetividades vinculadas a micro disputas de poder diante da cultura arraigada da defesa de pequenos feudos de conhecimento. Nesse sentido, compreende-se que o tempo de vivência deve extrapolar o tempo proposto em uma disciplina e adentrar em todo o processo formativo do licenciando.

Em todos os grupos a busca foi pelo desenvolvimento de MADEs pautados no desenvolvimento de apresentações. Apenas o G2 e o G5 utilizaram propostas diferentes com o Prezi e o simulador, porém, com o mesmo intuito, apresentar conteúdos. É 
importante ressaltar que no laboratório, os licenciandos têm acesso livre à internet e a tablets. Poderiam, portanto, ter escolhido o desenvolvimento de MADEs que façam uso de recursos on-line e de aplicativos móveis. A preocupação dos licenciandos nesse momento era de encontrar uma forma de apresentar o conteúdo aos alunos primeiramente, para que na sequência desenvolvessem outras atividades.

O centro da ação docente, portanto, em todos os grupos é o professor. É o docente que deve apresentar o conteúdo, gerenciar a informação, preparar o material da aula, conduzir a ação do aluno. Em nenhum MADE os licenciandos iniciaram o processo com uma atividade a ser realizada pelo aluno, com busca e construção de conhecimentos centrados na ação do aluno. E, mesmo que tivessem em mente esse tipo de ação, a atividade não foi incorporada nos MADEs, como se este material fosse de exclusividade do professor.

Diante da proposta evidenciada pela Unesco (2002), os licenciandos ainda se encontram nos primeiros estágios. É evidente que conhecem a internet e suas possiblidades de navegação, mas ainda não conseguem conectar os recursos digitais a propostas de materiais educacionais mais ousados que se diferenciem da proposta de apresentação do conteúdo por meio de slides. Esse aspecto parece influenciar ou ser influenciado pela metodologia utilizada na proposta de prática docente, corroborando com os relatos de Loureiro, Lima e Soares (2014) quando percebem o interesse de professores pelo uso das tecnologias digitais desprovido, porém, de inovações metodológicas.

\section{Considerações Finais}

Diante da busca pela análise de como os licenciandos da UFC compreendem a docência a partir do desenvolvimento de MADEs em contexto interdisciplinar perceberam-se algumas características importantes na relação que estabeleceram entre docência, interdisciplinaridade e TDICs.

Os licenciandos em geral fixaram-se na elaboração de slides para apresentação de conteúdos e, em algumas situações, utilizaram simuladores para a mesma finalidade. Mesmo com a possibilidade de expandir para outros recursos digitais, optaram por se manter em recursos comumente utilizados, até mesmo dentro da UFC. Apresentaram dificuldade em articular os conhecimentos de áreas diferentes, iniciando os MADEs diante de uma proposta interdisciplinar, sem conseguir prosseguir com a proposta de integração entre os diferentes saberes. Centraram-se, sobretudo, na produção de MADEs para uso do professor, evidenciando o centro da ação docente. Não cogitaram a possiblidade de desenvolvimento de atividades dentro dos MADEs para utilização pelos alunos.

Desde a Educação Básica até a formação docente na Universidade, os licenciandos se deparam com aulas expositivas, centradas na ação do professor [Tardif 2002]. Com a fragmentação curricular, a articulação entre diferentes saberes é inexistente [Gatti 2010]. A forma como os licenciandos desenvolvem os MADEs reflete sobremaneira como compreendem a docência, diante de toda a experiência teóricoprática de quase vinte anos como estudante. Nesse sentido, corrobora-se com Coll (2009), uma vez que desenvolvem as TDICs da mesma forma que pensam a docência, de forma expositiva, centrada na ação do professor.

De acordo com Lima (2014) é necessário que ocorram reflexões e ações para 
repensar as formações docentes, sobretudo a formação inicial, no sentido de incluir a articulação das TDICs com a docência em diferentes disciplinas dos cursos de Licenciatura, preparando o docente para uma ação mais próxima da realidade de seus alunos e de si mesmo, uma vez que todos estão incluídos em uma sociedade tecnológica digital, cibercultural. Nesse sentido, os dados obtidos com esse trabalho e os demais levantados pelo Grupo de Pesquisa Tecnodocência buscam contribuir no fornecimento de subsídios teóricos e empíricos para reflexões sobre o currículo dos cursos de Licenciatura, sobretudo com as discussões atuais sobre a Base Nacional Comum Curricular (BNCC) e a Extensionalização do Currículo.

Pretende-se continuar com a pesquisa sobre o desenvolvimento de MADEs e sua influência na compreensão do conceito de docência para os licenciandos da UFC com aprofundamento no estudo sobre a prática docente e a forma como os licenciandos utilizam os MADEs desenvolvidos quando em contato com alunos de escola pública.

\section{Referências}

Almeida, M. E. B. de; Valente, J. A. (2011) Tecnologias e currículo: trajetórias convergentes ou divergentes? São Paulo: Paulus.

Amem, B. M. V.; Nunes, L. C. (2006) Tecnologias de Informação e Comunicação: Contribuições para o Processo Interdisciplinar no Ensino Superior. Revista Brasileira de Educação Médica, v. 30, n. 3, p. 171-180.

Andalécio, A. M. L. (2009) Informação, Conhecimento e Transdisciplinaridade: mudanças na Ciência, na Universidade e na Comunicação Científica. Tese de Doutorado. Universidade Federal de Minas Gerais, Escola de Ciência da Informação, Belo Horizonte.

Ausubel, D. P; Novak, J. D.; Hanesian, H. (1980) Psicologia Educacional. Rio de Janeiro: Interamericana.

Barro, M. R.; Queiroz, S. L. (2012) Blogs no ensino de química: utilização e avaliação da aceitação em disciplina de comunicação científica. Revista Brasileira de Informática na Educação, v. 20, n. 2, p. 3-16.

Coll, C. (2009) Aprender y enseñar con las TIC: expectativas, realidad y potencialidades. In Carneiro, R.; Toscano, J. C.; Díaz, T. Los desafíos de las TIC para el cambio educativo. Madrid, España: Fundación Santillana, p. 113-126.

Czikszentmihalyi, M. (1990) Flow: the psychology of optimal experience. New York: Harper Perennial.

Foucault, M. (1979) A Microfísica do Poder. Rio de Janeiro: Edições Graal.

Gatti, B. A. (2010) Formação de Professores no Brasil: características e problemas. Educ. Soc., Campinas, v. 31, n. 113, p. 1355-1379, out.-dez. Disponível em: $<$ http://www.cedes.unicamp.br>. Acesso em: 02 abr. 2016.

Japiassu, H. (1976) Interdisciplinaridade e patologia do saber. Rio de Janeiro: Imago.

Karsenti, T.; Velleneuve, S.; Raby, C. (2008) O uso pedagógico das Tecnologias da Informação e da Comunicação na Formação dos Futuros Docentes no Quebec. Educ. Soc., Campinas, v. 29, n. 104 Especial, p. 865-889. Disponível em: $<$ http://www.cedes.unicamp.br>. Acesso em: 10 abr. 2016. 
V Congresso Brasileiro de Informática na Educação (CBIE 2016)

Anais do XXII Workshop de Informática na Escola (WIE 2016)

Lima, L. de. (2014) Integração das Tecnologias e Currículo: A Aprendizagem Significativa de Licenciandos de Ciências na Apropriação e Articulação entre Saberes Científicos, Pedagógicos e das TDIC. Tese de Doutorado. Programa de PósGraduação em Educação Brasileira, Universidade Federal do Ceará, Fortaleza.

Lima, L. de.; Loureiro, R. C. (2015) A integração entre Docência e Tecnologias Digitais da Informação e Comunicação na Formação de Licenciandos. Anais do XXI Workshop de Informática na Escola, Maceió.

Loureiro, R.; Lima, L. de; Soares, A. (2014) Docência Universitária no Contexto das Tecnologias Digitais da Informação e Comunicação. Anais do XIX Congreso Internacional de Informática Educativa. Brasil, Fortaleza.

Nascimento, S. P. do; Costa Junior, A. de O. (2015) Utilização do Visual Class como Recurso Didático Tecnológico na Educação de Jovens e Adultos (EJA). Anais do XXI Workshop de Informática na Escola, Maceió.

Papert, S. (2008) A Máquina das Crianças: repensando a escola na era da informática. Porto Alegre: Artmed.

Serres, F.; Basso, M. V. de A. (2009) Mídias Digitais de Comunicação: autoria e aprendizagem de Matemática. Anais do XV Workshop de Informática na Escola, Bento Gonçalves.

Stake, R. E. (1998) Investigación con estúdio de casos. Madrid: Morata.

Tardif, M. (2002) Saberes docentes e formação profissional. Petrópolis, RJ: Vozes.

Unesco. (2002) Information Communication Technology in Education: a curriculum for schools and programme of teacher development. Disponível em: http://unesdoc.unesco.org/images/0012/001295/129538e.pdf $>$. Acesso em: 15 dez. 2015 .

Valente, J. A. (2002) A Espiral da Aprendizagem e as Tecnologias da Informação e Comunicação: repensando conceitos. In: Joly, M. C. A Tecnologia no Ensino: implicações para a aprendizagem. São Paulo: Casa do Psicólogo Editora, p. 15-37.

Viseu, F.; Ponte, J. P. da. (2012) A Formação do Professor de Matemática, apoiada pelas TIC no seu Estágio Pedagógico. Bolema, Rio Claro (SP), v. 26, n. 42A, p. 329357.

Yin, R. K. (2005) Estudo de Caso: planejamento e métodos. Porto Alegre: Bookman. 